\title{
A Comparative Study of Open-Source and Licensed CAD Software to Support Garment Development Learning
}

\author{
Evridiki Papachristou ${ }^{1, *(\mathbb{D})}$, Panagiotis Kyratsis ${ }^{2} \mathbb{D}$ and Nikolaos Bilalis ${ }^{1}$ \\ 1 School of Production Engineering and Management, Technical University of Crete, 73100 Kounoupidiana, \\ Crete, Greece; nbilalis@isc.tuc.gr \\ 2 Department of Mechanical Engineering \& Industrial Design, Western Macedonia University of Applied \\ Sciences, 50100 Grevená, Greece; pkyratsis@teiwm.gr \\ * Correspondence: epapachristou@isc.tuc.gr
}

Received: 1 April 2019; Accepted: 26 April 2019; Published: 1 May 2019

\begin{abstract}
Most universities have included computer-aided design (CAD) pattern making systems education and training in their clothing technology courses in recent years, so as to respond to the actual needs of the fashion world for high-skilled fashion designers and clothing engineers. With the rapid rise in the use of open source software (OSS) in all types of applications, it is important to know if the existing OSS CAD software for garment prototyping development can successfully support the learning process. The present study compares two commercial licensed CAD systems for pattern design (Polypattern and Create) to an open source software, Seamly2D, and to Wild Ginger's Caveo V6 programme, which runs within an OSS. In total, two licensed and two OSS systems have been evaluated in their weights in accomplishing the garment development of ten different pattern designs. The results obtained for the evaluation of a set of OS and licensed CAD systems are presented and critically discussed.
\end{abstract}

Keywords: open-source CAD software; pattern design; licensed CAD; CAD teaching; teaching/learning strategies

\section{Introduction}

The skilled labour-dependent nature of apparel design, the globalisation of the market, the proliferation of information, the typical iterative "optimisation" trial-and-error process of apparel product development, the reduced time to market and continuous pressures of cost are just some of the factors that add to the fashion industry's already complex activities. Digital prototypes in the textile and clothing industry are part of the technology adoption in the product development process, a process that involves various operators in different stages and places, with various skills and competencies and different necessities of formalising and defining in a deterministic way the result of their activities [1]. Taking into account the recent trends in the industry, the product development cycle and the use of new digital technologies cannot be restricted in the "typical cycle", but additional tools and skills require integration for these developments to be taken into account [2].

Since the fashion industry is the most skilled labour-dependent industry, and any cost saving through new computer-aided design (CAD) technologies has become a requirement in gaining a competitive advantage, most universities have included CAD pattern making systems education and training as part of their clothing technology courses in recent years, so as to respond to the actual needs of the fashion world for high-skilled fashion designers and clothing engineers. CAD/CAM (Computer Aided Manufacture) systems allow a design to be generated rapidly and adjusted equally 
quickly without diminishing creativity, and provide better communication and integration between product development systems [3]. They have been instrumental in reducing lead times, improving accuracy, and putting apparel products in retail stores much closer to the time they are needed by the consumer [4].

With the rapid rise in the use of open source software (OSS) in all types of applications, it is important to know if the existing OSS CAD software for garment prototype development can successfully support the learning process. Summers and Shah [5] noted that an objective assessment of CAD model complexity can be useful in assessing case studies, evaluating the results of experiments, or evaluating student projects. Several other authors have highlighted the likely effects of CAD model complexity [6-8]. Johnson, Valverde and Thomison [9] noted that modelling procedure includes the amount of time spent engaging in particular modelling activities. The amount of time required to create a CAD model has been reported and used as a metric for CAD modelling [10-12] and alteration $[13,14]$ quality. The number of operations is a proxy for the number of features or operations required to create a specific piece of CAD geometry. The present study compares commercial licensed CAD systems for pattern design to an open source software, Seamly2D [15], and to MacroGen's Cameo v6 [16] programme which runs within an OSS. This assessment could be taken into account when assessing development timelines in academic projects, especially in institutions where sources for licensed CAD software are limited, or for students who want to practise and/or use a CAD apparel prototype system outside institutions' premises. In total, two licensed and two OSS systems have been evaluated in their weights in accomplishing the garment development of ten different pattern designs. The results obtained for the evaluation (based on the metric of time) of a set of OS and licensed CAD systems are presented and critically discussed.

\section{CAD-Based Design Skills for Fashion Education}

Textile engineering (TE) and fashion technology (FT) educational programmes are always undergoing continuous formal assessment under different accreditation bodies. ABET (Accreditation Board for Engineering and Technology) [17], recommend seven student outcomes, concerning the content of a course (or a series of courses). Traditional computer aided design (CAD) and drawing courses introduce mainly geometric modelling using wireframe, surface, and solid modelling. Ullah and Harib [18] suggested that the content of a course regarding CAD/CAM should help students attain at least the following four outcomes: (1) an ability to apply the knowledge of mathematics, science, and engineering; (2) an ability to design a system, component, or process to meet the desired needs; (3) an ability to identify, formulate, and solve engineering problems; and (4) an ability to use the techniques, skills, and modern engineering tools necessary for engineering practice. The same authors [18], proposed a customised, software-free methodology for teaching design and manufacturing in the field of engineering, but their research addresses the issue of integrating advanced machine tools (e.g., hexapod-based machine tools) with solid modelling. Garment prototyping and digital pattern development has taken place in commercial CAD tools with surface modelling.

Open-source CAD software has emerged in many fields as a promising alternative to commercial and licensed off-the-shelf systems, but college and universities' courses in fashion design and textile engineering still depend the effectiveness of such courses on teaching the effective design approach based on licensed pattern design CAD software-licenses with a usual high cost even as educational forms.

Almost every bachelor's and master's degree course in the industrial and mechanical engineering areas include at least one computer-design class, wherein students can learn CAD-based design principles. Many universities adopt even three-dimensional (3D) CAD licensed software primarily to keep close contact with the industry environment, the place where CAD skill and expertise are actually requested [19]. Two-dimensional (2D) CAD software, such as Autodesk AutoCAD, is fundamental, and to many countries like Spain, according to [20], all the major 3D CAD licensed software is used at all the industrial schools. In fashion and textile engineering, however, $3 \mathrm{D}$ software is not so popular yet, 
but 2D CAD software tools, such as Lectra's Modaris [21], Gerber's Accumark [22], Crea's Create [23], Polytropon's Polypattern [24], and Optitex's PDS [25], provide fashion students with knowledge on:

- development principles and functions;

- the principles of garment pattern design;

- the rules of pattern design by size;

- the definition of a style and its versions;

- marker making;

- creating markers on fabrics with definition and changing parameters;

- preproduction garment specifications;

- preparation of pattern blocks for 3D simulation in 3D virtual prototype tools.

The teaching of commercial CAD systems for garment development in combination with draping and fitting evaluation has already been tested successfully. Those fashion students could design and develop their virtual 3D-model ideas from the CAD software directly into physical 3D physical garment prototypes. Thus, the students could improve their understanding of design rules suitable for draping and proper fitting. However, all CAD-licensed software has a limited useful life, since they are bound to become obsolete in time given the constant update of operating systems and the unstoppable growth of hardware and software and the improvement of their performance in a very demanding and competitive race [19]. CAD vendors for garment development release new versions in order to offer new features and guarantee a state-of-the-art performance. As a consequence, however, more often than not, universities are compelled to hold back updates because of the costs in which hardware and software entail.

\section{Methodology}

As a first step, comprehensive internet research was conducted along with the literature research as an inquiry into freeware and OSS tools. It came as a surprise that although a relatively large number of software tools exist for other disciplines like mechanical, electronic, or industrial engineering, similar tools for apparel pattern development were hard to find. Moreover, reviews on open source and freeware CAD systems for disciplines other than fashion and clothing have already been done, for example, Junk \& Kuen [26] have researched OSS for 3D Printing. Subsequently, a search for classification of open source CAD systems available online for pattern drafting have verified that the only CAD open-source, parametric, variational, feature-based, and procedural software available (15 December 2017) is Seamly2D. Another CAD software tool which was chosen for evaluation and comparison was Wild Ginger's Cameo v6, as it is not such a costly educational version when compared with the other licensed CAD software tools.

The licensed tools that were used to complete the comparison and evaluation were Crea's Create for 2D CAD pattern development and Polytropon's Polypattern. Students were shown a demonstration of all the software solutions, and after the completion of their learning process the students that were most efficient in the use of the tools and understanding of garment pattern developing were selected to participate in the research.

Seamly2D (formerly Valentina) is a patternmaking cross-platform programme that allows the development of garment patterns by professional designers or individual users. The software allows the user to insert his/her individual set of measurements or to use standard sizing tables as another option. The programme runs on Windows, Mac OSX, and Ubuntu, and is downloadable. Seamly2D can provide any sewer or clothing manufacturer the opportunity to create and develop digital patterns of any garment style; it can be easily downloaded from the internet and offers support in the context of using the interface and its tools. According to its forum [27], Seamy2D's open data formats and collaborative culture enables independent designers to become ethically profitable, and can empower designers focused on eco fashion and slow fashion. Another advantage of downloading Seamly2D and creating digital patterns with it instead of choosing a licensed and costly software is that independent 
small designers and manufacturers can create small-batch and custom-sized clothing collections which are essential to create a sustainable future. This way, local garment districts can be rebuilt, can reduce or eliminate low-wage labour and unethical working conditions, and even scale up to bigger productions.

Wild Ginger's Cameo v6 Pattern Design is an apparel pattern development software for professional pattern makers. Cameo's apparel production tools allow users to draft and edit patterns, customise size or grade patterns, lay markers, and create technical drawings and specifications. The software solution allows pattern creation and modification by anyone having appropriate skills. It contains all the tools that a pattern maker needs, such as the creation and transfer of darts, slash/spread, adding seam allowance, and pattern marking. Cameo is not an open source tool; it is sold in modules and libraries. Cameo runs only in Windows and, for the purpose of the research, the authors worked in the downloadable demo version of the software.

From observing Cameo v6's webpage, it is clear that the specific software is mainly focused on new CAD pattern making users and/or students as it suggested in the Digital Flat Pattern: The Apparel Designer's Handbook. This instruction book, which is not free, provides instructions for creating patterns for a wide range of styles-including bodices, dresses, jackets, skirts, pants, sleeves, collars, and pockets. Although, as mentioned above, the CAD software is not an OSS, its price is more affordable compared with other commercial programmes, and it includes free tutorial CAD software and example files for completing all styles illustrated in the book.

\subsection{Aim of the Research}

The aim of this research was to evaluate the usability of the existing OSS CAD software for garment prototype development and see if it can successfully support the learning process compared with two licensed forms of software. The metric used was the amount of time required to create a specific garment in all four CAD systems (Table 1). In order to do so, fourth year students with the knowledge of all four systems were asked to create 10 different digital patterns at the end of their learning process of CAD modelling in garment pattern making.

Table 1. Developing time for each style and each CAD system.

\begin{tabular}{ccccc}
\hline \multicolumn{5}{c}{ Time in Minutes for Each Pattern Cutting Programme } \\
\hline Type of Garment & Seamly2D & Cameo V6 & Polypattern & Crea \\
\hline Straight skirt & $30^{\prime}$ & $8^{\prime}$ & $5^{\prime}$ & $13^{\prime}$ \\
\hline Culottes & $45^{\prime}$ & $20^{\prime}$ & $9^{\prime}$ & $46^{\prime}$ \\
\hline Basic trousers & $3 \mathrm{~h}$ & $32^{\prime}$ & $20^{\prime}$ & $45^{\prime}$ \\
\hline Tracksuit trousers & $13^{\prime}$ & $12^{\prime}$ & $5^{\prime}$ & $13^{\prime}$ \\
\hline $\begin{array}{c}\text { Close fitting } \\
\text { bodice block }\end{array}$ & $40^{\prime}$ & $20^{\prime}$ & $20^{\prime}$ & $9^{\prime}$ \\
\hline Tracksuit top & $15^{\prime}$ & $19^{\prime}$ & $8^{\prime}$ & $19^{\prime}$ \\
\hline Basic shirt & $55^{\prime}$ & $1 \mathrm{~h} 7^{\prime}$ & $1 \mathrm{~h} 10^{\prime}$ & $58^{\prime}$ \\
\hline Vest & $1 \mathrm{~h}$ & $40^{\prime}$ & $35^{\prime}$ & $26^{\prime}$ \\
\hline Tailored jacket & $45^{\prime}$ & $33^{\prime}$ & $45^{\prime}$ & $45^{\prime}$ \\
\hline Two-piece sleeve & $30^{\prime}$ & $20^{\prime}$ & $35^{\prime}$ & $23^{\prime}$ \\
\hline
\end{tabular}

\subsection{Literature Research}

In other sectors (i.e., mechanical engineering) companies commonly organise tailored courses and training sessions in collaboration with leading global vendors in order to achieve a deeper knowledge on specific CAD-based software for specific fields of application according to the professional profile and the level of expertise of their users [28]. Such an approach, however, is not completely satisfactory, since it produces very well-trained CAD users but, often, does not take care of either the design 
thinking [29] or the linguistic basics [30] needed to fully exploit CAD performance. On the contrary, in the fashion industry, garment development learning and pattern design skills can be obtained through higher education fashion courses. Digital pattern development can be taught individually by CAD-software companies and their training teams, by attending a pattern design course (full-time, part-time, seminar) in a college, or attending an online course. Most of the higher educational institutes that provide fashion courses or clothing technology courses have access to educational licenses of CAD software for pattern development. However, according to [31], online education is increasingly becoming a dominant part of our education system.

\subsection{Problem Statement}

Leaving aside the question of the economic and ethical implications of adopting open-source software instead of licensed software, the issue addressed in the present paper is connected to the following question: Can any open-source CAD system for developing clothing patterns effectively support university courses when the teaching focus needs to be on the method rather than on the instrument itself?

In order to evaluate the performance of a 2D CAD system, the authors established a comparison between the already taught commercial CAD systems, an open-sourced software, and a fairly accessible -in terms of price-software available to fashion students. In a design-oriented approach, CAD students need to complete the assigned tasks by using the various tools available within the CAD environment. Hence, a CAD system is considered compliant with design education and training if it offers all the tools requested for modelling and drawing clothing products. The related CAD workbenches are thus considered:

- New pattern creation-the workbench to draw a new pattern piece from scratch with specific measurements;

- Insert new points and notches—-the workbench to put grading and curve points on any place of the pattern;

- Measuring-the workbench to evaluate if a specific distance is correct;

- Curves-the workbench to model curves;

- Editing - the workbench to edit any part of the pattern by move, cut, unite, rotate, mirror, etc.;

- Darts, folds and gathers - the workbench to create, edit, and delete darts, and to fold and gather to any point of the garment.

The method workflow consists of three steps:

1. Selection of the basic pattern blocks in a standard size (12) that the students have the skills to develop digitally.

2. Development of prototype patterns in all four CAD systems through monitoring the passage of time for every task and every different CAD system.

3. Analysis of the results with respect to the time, efficiency, and number of steps.

\section{Results}

\subsection{Selection of Basic Pattern Blocks in a Standard Size 12}

Basic block patterns in a standard size 12 [32], were used to develop designs for the prototypes based on the instruction of metric pattern cutting of Winifred Aldrich [33]. More specifically, 10 styles were decided to be developed in all four programmes:

1. Straight skirt, 2. culottes 3. basic trousers, 4. tracksuit trousers, 5. close fitting bodice block, 6. tracksuit top, 7. basic shirt, 8. vest, 9. the tailored jacket block, and 10. two-piece sleeve block.

Seam allowance was only put where it was permitted by the software. Grading was omitted, since it was not supported by the four and was not part of the current research. Size 12 was indicated 
as appropriate, therefore the basic block for each individual garment was based on the body measures of a size 12 (UK).

4.2. Development of Prototype Patterns in All Four CAD Systems with Monitoring the Passage of Time for Every Task and Every Different CAD System

Figures 1 and 2 show the digital patterns of the previous selection in the Polypattern CAD system:

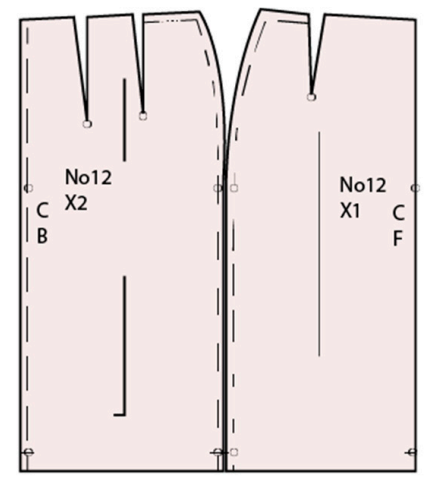

(a)

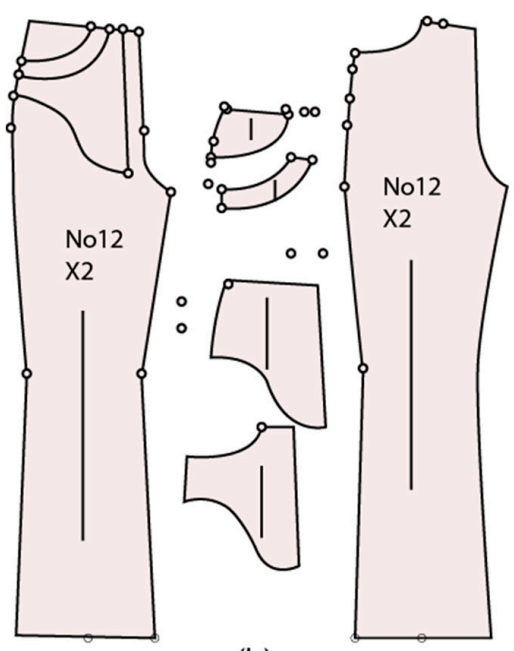

(b)

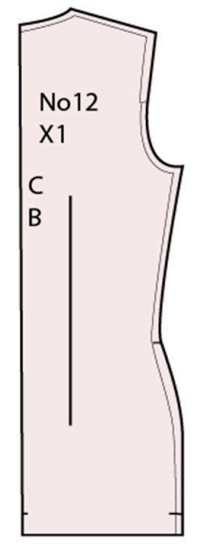

(d)



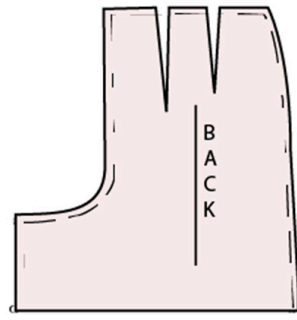

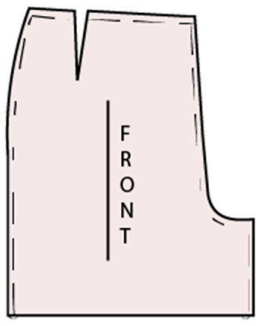

(c)
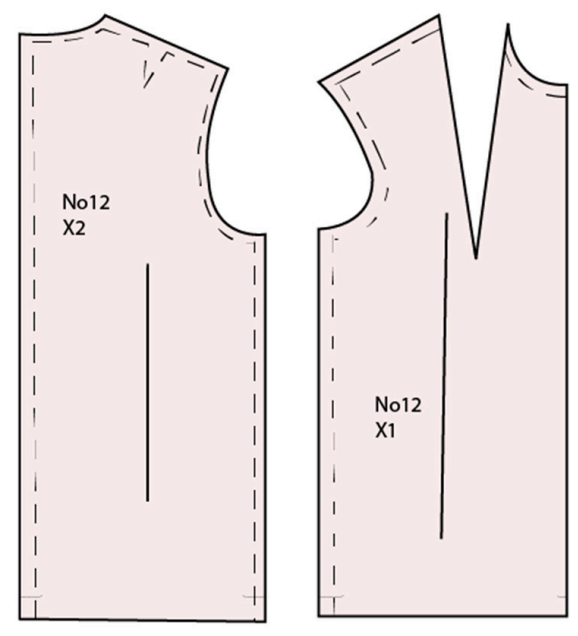

(f)

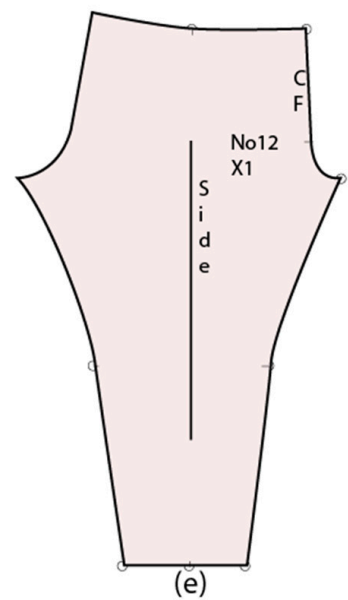

Figure 1. Polypattern computer-aided design (CAD): basic skirt (a), basic trousers (b), culottes (c), track-suit top (d), tracksuit trousers (e), close-fit bodice block (f). 



(c)
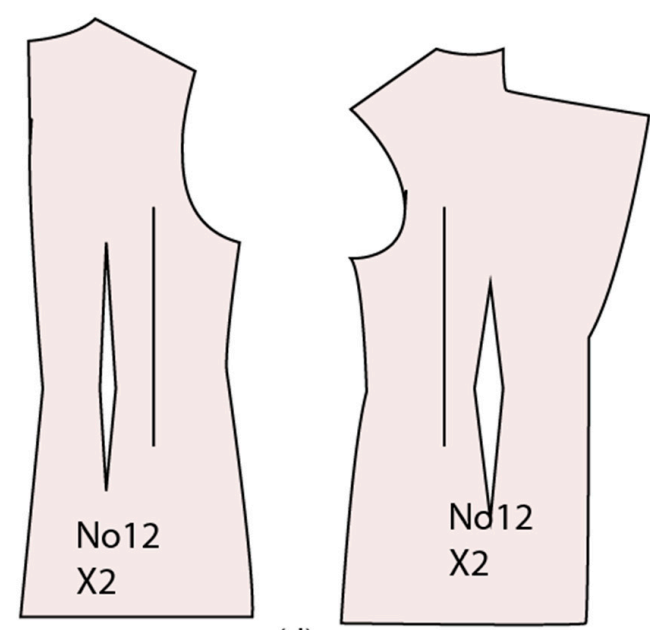

(d)

Figure 2. Polypattern CAD: basic shirt (a), vest (b), two-piece sleeve (c), basic jacket block (d).

\subsection{Analysis of the Results with Respect to the Time, Efficiency, and Number of Steps}

From the results obtained when analysing and comparing Seamly2D and Wild Ginger's Cameo v6 with the licensed Polypattern and Create, it has been concluded that currently this open-source CAD has not reached a sufficient level to replace commercial licensed parametric, variational, feature-based, and procedural CAD systems in academic courses. This is mainly because it lacks the implementation of some strategic tools:

- Creation of a new pattern piece: The development method in the non-licensed software (Seamly2D and (ameo) has many similarities to the traditional pattern development by hand. Above all, it is time consuming. 
- New point and notch inputs: All four software tools have different ways to put a new point or a notch on a pattern. However, moving a point takes longer in Seamly2D and Cameo.

- Measure tape: The ruler and measure tape for distances and curves is one of the basic tools of a programme. However Seamly2D does not support such a feature.

- Create curves: All four programmes can easily create curves

- Section move: Too complicated for Seamly2D, feasible in Cameo, easier in Polypattern and Crea

- Darts, folds and gatherings: The easier way to create them is in Crea and Polypattern. Open source Seamly2D needs to create a new pattern from the beginning and the exact distances for every new point are required by the user. Cameo requires multiple moves; the functions are not automatic.

- Cut and unite of pattern pieces: Seamly2D cannot unite cut pieces. Comparing all four, Polypattern provides the easiest and more efficient method.

- Rotation of pattern pieces: Seamly2D cannot rotate; the other three can do this easily.

- Seams: An older version of Seamly2D had a tool for seam allowance. The newer version has none. Cameo also lacks this function. If the user wants to add seams, they need to create parallel lines with the desired distance. Polypattern and Crea provide the seam allowance with three clicks.

- Sizing: Seamly2D and Cameo cannot cover this very important need for a pattern developer. Crea and Polypattern are both focused in satisfying the demands of creating complex styles in a rapid changing manufacturing environment like the one of apparel.

\section{Conclusions}

OSS for garment pattern development is still at an experimental stage. While such software can manipulate standard demands in digital garment prototyping-such as the creation of a new pattern piece from the beginning and drawing lines-dealing with commands such as cutting, rotating, adding seam allowance, and especially grading in other sizes, is still problematic. Procedures in OSS are complicated and follow the mentality of doing the pattern by hand. Within the experimental work, certain processes could only be done in licensed CAD systems and not in OSS. For example, section distance measuring could be done only in Polypattern, Crea, and Cameo, but not in OSS Seamly2S. The study found that the creation of darts, folds, and fabric gathering in OSS was by trial and error. Although prescribed procedures were followed, the control of adding seam allowance or moving a section was problematic, as the tutorial for Seamly2D referred to an older version that probably provided the function, but was no longer found in the newer version. Two-dimensional pattern design software based on flat patternmaking techniques has been successfully explored for patternmaking, grading, and creating pattern libraries within software for future retrieval [34]. More importantly, grading in different sizes, which is an irreplaceable tool and command for pattern developers in the fashion industry, is simplified as a process only in professional licensed CAD systems. Wild Ginger lacks this function, catering well to the needs of only small garment units, boutiques, and custom apparel makers. Measurements need to be put into the system to obtain the pattern block. OSS, like Seamly 2D, cannot successfully support the learning process. Unless the complexity decreases, and the OSS project employs a modular approach to software production, the project becomes less attractive to new users, resulting in a technical success decrease. Academic institutions, in order to prepare fashion students for situations they will face once they have entered the job market, need to provide the industry-based experiential-learning opportunities required for translating innovative designs into marketable garments. OSS tools for garment prototyping need further development in order to achieve this goal.

Author Contributions: Data curation, E.P.; Formal analysis, E.P.; Investigation, E.P.; Methodology, E.P.; Resources, P.K.; Supervision, N.B.; Writing一review \& editing, E.P.

Funding: This research received no external funding.

Conflicts of Interest: The authors declare no conflict of interest. 


\section{References}

1. Papachristou, E.; Bilalis, N. 3D virtual prototyping traces new avenues for fashion design \& product development-A qualitative study. J. Text. Sci. Eng. 2017, 6, 297. [CrossRef]

2. Papachristou, E.; Bilalis, N. Can 3D prototype conquer the apparel industry? J. Fash. Technol. Text. Eng. 2016, 4, 2. [CrossRef]

3. Istook, C. Rapid prototyping in the textile \& apparel industry: A pilot project. J. Text. Appar. Technol. Manag. 2000, 1, 1 .

4. Bae, J.; May-Plumplee, T. Customer focused textile \& apparel manufacturing systems: Toward an Effective e-commerce model. J. Text. Appar. Technol. Manag. 2005, 4, 1-19.

5. Summers, J.D.; Shah, J.J. Mechanical Engineering Design Complexity Metrics: Size, Coupling, and Solvability. J. Mech. Des. 2010, 132, 021004. [CrossRef]

6. Amadori, K.; Tarkian, M.; Ölvander, J.; Krus, P. Flexible and robust CAD models for design automation. Adv. Eng. Inform. 2012, 26, 180-195. [CrossRef]

7. Bodein, Y.; Rose, B.; Caillaud, E. A roadmap for parametric CAD efficiency in the automotive industry. Comput. Aided Des. 2013, 45, 1198-1214. [CrossRef]

8. Bodein, Y.; Rose, B.; Caillaud, E. Explicit reference modeling methodology in parametric CAD system. Comput. Ind. 2014, 65, 136-147. [CrossRef]

9. Johnson, M.D.; Valverde, M.L.; Thomison, D.W. An investigation and evaluation of computer-aided design model complexity metrics. Comput.-Aided Des. Appl. 2018, 15, 61-75. [CrossRef]

10. Diwakaran, R.P.; Johnson, M.D. Analyzing the effect of alternative goals and model attributes on CAD model creation and alteration. Comput.-Aided Des. 2012, 44, 343-353. [CrossRef]

11. Hamade, R.F.; Ammouri, A.H.; Artail, H. Toward pre-dicting the performance of novice CAD users based on their profiled technical attributes. Eng. Appl. Artif. Intell. 2012, 25, 628-639. [CrossRef]

12. Hamade, R.F.; Artail, H.A.; Jaber, M.Y. A study of the impact of the willingness-to-learn of CAD novice users on their competence development. Comput. Ind. Eng. 2011, 61, 709-720. [CrossRef]

13. Camba, J.D.; Contero, M.; Company, P. Parametric CAD modelling: An analysis of strategies for design reusability. Comput.-Aided Des. 2016, 74, 18-31. [CrossRef]

14. Johnson, M.D.; Diwakaran, R.P. An educational exercise examining the role of model attributes on the creation and alteration of CAD models. Comput. Educ. 2011, 57, 1749-1761. [CrossRef]

15. Seamly2D. Available online: http://valentina-project.org/ (accessed on 10 October 2017).

16. Cameo v.6 (Wild Ginger). Available online: https://www.wildginger.com/downloads/cameo6download.htm (accessed on 10 October 2017).

17. ABET. Available online: https://www.abet.org/accreditation/accreditation-criteria/criteria-for-accreditingengineering-programs-2019-2020/\#GC3 (accessed on 20 January 2019).

18. Ullah, S.; Harib, K. Tutorials for Integrating CAD/CAM in Engineering Curricula. Educ. Sci. $2018,8,151$. [CrossRef]

19. Di Angelo, L.; Di Stefano, P.; Leali, F. Can Open-Source 3D Mechanical CAD Systems Effectively Support University Courses? Int. J. Eng. Educ. 2016, 32, 1313-1324.

20. Garcia, R.R.; Santos, R.G.; Quiros, J.S.; Penin, P.I.A. Present state of CAD teaching in Spanish Universities. Comput. Educ. 2005, 44, 201-215. [CrossRef]

21. Modaris, Lectra. Available online: https://www.lectra.com/en/modaris (accessed on 2 October 2017).

22. Accumark Gerber Technologies. Available online: http://www.gerbertechnology.com/fashion-apparel/plan/ accumark/ (accessed on 3 May 2018).

23. Crea Solution. Available online: http://www.creasolution.it/en/products/design/2d-cad-fashion/?lang=en (accessed on 25 March 2018).

24. Polypattern Polytropon. Available online: http://www.polytropon.com/en/PolyPattern/cad-pattern-designsoftware.html (accessed on 25 March 2018).

25. Optitex. Available online: https://optitex.com/solutions/odev/pattern/ (accessed on 25 March 2018).

26. Junk, S.; Kuen, C. Review of Open Source and Freeware CAD Systems for Use with 3D-Printing. Procedia CIRP 2016, 50, 430-435. [CrossRef]

27. Seamly. Available online: https://seamly2d.wordpress.com/about/ (accessed on 20 January 2019). 
28. Field, D.A. Education and training for CAD in the auto industry. Comput.-Aided Des. 2004, 36, $1431-1437$. [CrossRef]

29. Katz, R. Integrated thinking in mechanical engineering education. Int. J. Eng. Educ. 2015, 31, 1613-1621.

30. Cheng, N. Teaching CAD with language learning methods. Acadia 1997, 97, 173-188.

31. Singh, V.; Holt, L. Learning and best practices for learning in open-source software Communities. Comput. Educ. 2013, 63, 98-108. [CrossRef]

32. Beazley, A. Size and fit: The development of size charts for clothing_Part 3. J. Fash. Mark. Manag. 1999, 3, 66-84. [CrossRef]

33. Aldrich, W. Metric Pattern Cutting for Women's Wear, 6th ed.; Wiley: Hoboken, NJ, USA, 2015.

34. Jhanji, Y. Computer-aided design-Garment designing and patternmaking. In Automation in Garment Manufacturing; Nayak, R., Padhye, R., Eds.; A Volume in the Textiles Institute Book Series; Technological Institute of Textile and Sciences: Bhiwani, India, 2018; pp. 253-290.

(C) 2019 by the authors. Licensee MDPI, Basel, Switzerland. This article is an open access article distributed under the terms and conditions of the Creative Commons Attribution (CC BY) license (http://creativecommons.org/licenses/by/4.0/). 